\title{
Problems in the detection of carriers of haemophilia A
}

\author{
DOMINIQUE MEYER, A. PlAS ${ }^{1}$, J. P. Allain ${ }^{2}$, G. M. SITAR ${ }^{3}$, AND \\ M. J. LARRIEU \\ Laboratoire de Coagulation (IHTC of the World Federation of Haemophilia), Institut de Pathologie \\ Cellulaire, Hôpital de Bicêtre, 94270 Le Kremlin Bicêtre, France
}

SYNOPSIS Factor VIII activity and factor VIII related-or Willebrand-antigen were studied in 49 known carriers of haemophilia A and 31 normal women, and the data were analysed by four statistical approaches. Sixteen per cent of normals and $18 \%$ of carriers were misclassified, overlapping with the other group.

Although the percentage of carriers detected is higher when taking into account the results of both biological and immunological factor VIII, it is lower than others recently reported, and the discrepancies between the results obtained are discussed.

Haemophilia A is X-chromosome linked and is characterized by decreased plasma factor VIII (antihaemophilic factor A) levels as measured by specific clotting assays. The detection of carriers of haemophilia A remains a difficult and still controversial problem. Previous attempts at defining them have depended upon the measurement of factor VIII clotting activity (Soulier and Josso, 1966). It has been shown that, as a group, carriers have a lower mean factor VIII activity than normal women; however, only $40-50 \%$ of carriers have low factor VIII values; there exists a large overlap between normals and carriers which may be related to the technical inadequacies of factor VIII determination and random inactivation of one of the two X chromosomes (Lyon, 1961 ; Russell, 1964). Furthermore, factor VIII varies widely in normal women (Ingram, 1965) as well as in carriers. As a result, this method alone is unsatisfactory since it allowed the detection of only $30-40 \%$ of carriers.

Recent studies (Zimmerman et al, 1971a; Stites et al, 1971; Meyer et al, 1972; Hoyer, 1972) have demonstrated the presence of normal or increased amounts of an inactive protein, antigenically similar to normal factor VIII, in the plasma of all haemo-

${ }^{1}$ Département de Chimie Biologique (INSERM U. 33), Hôpital de Bicêtre, France

'Centre pour enfants hémophiles, Croix Rouge Française, 78940 La Queue les Yvelines, France

3Present address: Università di Pavia, Clinica Medica Generale e Terapia Medica, 27100 Pavia, Italy

Received for publication 10 February 1975. philia A patients tested. This protein is called 'factor VIII-related antigen' or 'Willebrand antigen? since it is present in normal individuals and haemo philia $\mathrm{A}$ patients and absent in patients with vop Willebrand's disease. Using a quantitative immuno? logical assay, Zimmerman et al (1971b) have shown that the ratio between factor VIII activity and Willebrand antigen was significantly lower in the cryoprecipitate of known carriers than of normal women. This ratio allowed Zimmerman et al (1971b) to identify with $99 \%$ certainty $92 \%$ of obligatory carriers. These data have been confirmed and extended to a larger series of heterozygotes by Bennett and Ratnoff (1973).

Factor VIII activity and Willebrand antigen were studied in 49 known carriers of haemophilia $\mathrm{A}$ and 31 normal women. Although in agreement with previous reports when the mean results of the two populations are considered, many problems concerning the discrimination of carriers from normal women remain. Therefore our data have been submitted to four different statistical approaches. An evaluation of their validity both in defining each population and in detecting the carrier state on an individual basis was attempted.

\section{Materials and Methods}

The group of carriers included 49 obligatory carriers (daughters of haemophiliacs, women with more than one affected son or with one affected son and a family history of haemophilia). None of the carriers was 
known to be pregnant. The control group included 31 non-pregnant females, laboratory and hospital personnel with no familial or personal bleeding tendency.

\section{FACTOR VIII ASSAY}

Blood was anticoagulated with $3.8 \%$ trisodium citrate ( 1 volume: 9 volumes blood); the plasma was separated by centrifugation at $3000 \mathrm{~g}$ for 20 minutes at $+4^{\circ} \mathrm{C}$. The assay of factor VIII activity was carried out on fresh plasma within 3 hours after sampling with a modification of the partial thromboplastin time using kaolin and haemophilia A plasma (factor VIII $<1 \%$ ) as substrate. Normal range: $50-200 \%$. The rest of the plasma was stored at $-85^{\circ} \mathrm{C}$ and used for Willebrand antigen assay. All determinations were done in blind and duplicate. Standard reference plasma was a pool of plasmas from 20 normal women (age $20-55$ years) kept at $-85^{\circ} \mathrm{C}$ for no longer than two months. The same pool served as reference for the measurement of both factor VIII activity and Willebrand antigen.

\section{WILLEBRAND ANTIGEN ASSAY}

An antiserum to normal purified factor VIII was raised in rabbits and absorbed as previously described (Meyer et al, 1972). Such an antiserum reveals the existence of only one line of precipitation, present in normal and haemophilia A plasma, and lacking in von Willebrand's disease plasma. Assay of Willebrand antigen was carried out on fresh or frozen $\left(-85^{\circ} \mathrm{C}\right)$ plasma by a modification of the Laurell (1966) quantitative immunoelectrophoretic technique using the previously described antiserum. Instead of measuring the antigen on cryoprecipitate (Zimmerman et al, 1971b), our modification was to use plain plasma at different dilutions $(1 / 2,1 / 4,1 / 8$, and $1 / 16$ ) deposited in a single well (diameter $3 \mathrm{~mm}$ ) (Meyer et al, 1974). All determinations were done in blind and triplicate.

STATISTICAL ANALYSIS

The contingence table was calculated according to
Fisher (1936). The distribution of the mean ratio of factor VIII activity to Willebrand antigen and of the weighted mean of difference between the two entities were performed as described by Snedecor and Cochran (1967) using the rule of optimized decision of Bayes, described by Peterson (1965). Tolerance ellipses were calculated according to Seal (1968). The discriminant analysis was performed using a computer for treatment of the data. The distance $\left(\lambda^{2}\right)$ of each individual point was calculated to the centrum of both ellipses, and each normal or carrier tested was affected to the group corresponding to the smallest distance, as measured with the equation of the ellipses. The confidence probability for each individual point to belong to one or the other group was estimated with the chi square table (Cramer, 1967) (freedom degree: 2) since $\lambda^{2}$ had a distribution corresponding to it.

\section{Results}

POPULATION ANALYSIS

Results of factor VIII activity, Willebrand antigen, specific ratio (factor VIII activity to Willebrand antigen), and difference between Willebrand antigen and factor VIII activity are listed in table I. As a mean, factor VIII activity and the specific ratio are lower in carriers than in normals. The difference between the two entities is significantly higher in carriers. Contrarily, Willebrand antigen is similar in both groups. In carriers of severe haemophilia $\mathbf{A}$ (table I), the mean of both factor VIII activity and Willebrand antigen appears lower than in carriers of moderate haemophilia A, or of haemophilia A with antibody to factor VIII, but these results may be of no significance since the number of carriers in the last two groups is small.

\section{INDIVIDUAL ANALYSIS}

The data obtained in normal women and carriers have been submitted to four different statistical approaches.

\begin{tabular}{|c|c|c|c|c|c|}
\hline & $\begin{array}{l}\text { Factor VIII } \\
\text { Activity } \\
\%\end{array}$ & $\begin{array}{l}\text { Willebrand } \\
\text { Antigen } \\
\%\end{array}$ & Ratio & Difference & \\
\hline $\begin{array}{l}\text { Normals } \\
\text { Carriers of haemophilia } \\
\text { Severe (35) } \\
\text { Moderate (7) } \\
\text { With antibody (7) }\end{array}$ & $\begin{array}{l}93.81 \pm 0.251 \\
61.09 \pm 3.26 \\
59.35 \pm 3.89 \\
65.85 \pm 8.43 \\
66.78 \pm 5.42\end{array}$ & $\begin{array}{r}96.62 \pm 0.25 \\
96.70 \pm 3.66 \\
92.5 \pm 4.07 \\
100.00 \pm 11.78 \\
109.67 \pm 9.42\end{array}$ & $\begin{array}{l}0.98 \pm 0.17 \\
0.64 \pm 0.29 \\
0.68 \pm 0.04 \\
0.67 \pm 0.11 \\
0.64 \pm 0.08\end{array}$ & $\begin{array}{r}2 \cdot 90 \pm 2 \cdot 40 \\
33 \cdot 64 \pm 7 \cdot 65 \\
23 \cdot 39 \pm 4 \cdot 77 \\
42 \cdot 26 \pm 14 \cdot 11 \\
49 \cdot 17 \pm 15 \cdot 60\end{array}$ & $\begin{array}{l}\left(\mathrm{NS} 5.10^{-2}\right) \\
\left(\mathrm{S}<1.10^{-4}\right)\end{array}$ \\
\hline
\end{tabular}

Table I Results of factor VIII activity, Willebrand antigen, specific ratio (factor VIII activity to Willebrand antigen), and difference between Willebrand antigen and factor VIII activity in 31 normals and 49 carriers, according to the type of haemophilia $A$ (35 carriers of severe haemophilia A; 7 carriers of moderate haemophilia A; 7 carriers of haemophilia $A$ with antibody to factor VIII)

'Mean \pm SEM 


\section{Fisher's Contingence Table}

When taking into account the results of both populations together, the weighted mean of factor VIII activity and Willebrand antigen is respectively $74.9 \%$ and $96.6 \%$. Using Fisher's contingence table (table II), the percentage of misclassification is $19.8 \%$ among normals ( 6 out of $31=$ cases $2,5,6,13$, and 21 ) and $26.5 \%$ among carriers (13 out of $49=$ cases $5,6,7,12,13,19,24,28,33,38,43,46$, and 49).

\section{Distribution of the Ratio of Factor VIII Activity to Willebrand Antigen}

Figure 1 shows the distribution of this specific ratio, with the determination of the optimized limit of

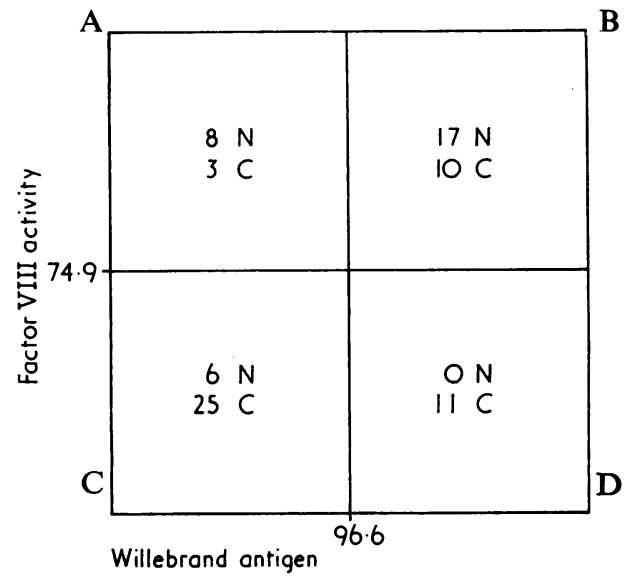

Table II Fisher's contingence table. Weighted mean of factor VIII activity $(74.9 \%)$ and Willebrand antigen (96.6\%). Percentage of misclassification : $19.8 \%$ for normals $(N)$ and $26.5 \%$ for carriers $(C)$

The weighted mean of factor VIII activity is

$\bar{y}=\frac{\left(n_{N} \bar{y}_{N}\right)+\left(n_{C} \bar{y}_{C}\right)}{\left(n_{N}+n_{C}\right)}=74.90$

$\mathrm{n}=$ number of cases

The weighted mean of Willebrand antigen is

$\overline{\mathrm{x}}=\frac{\left(\mathrm{n}_{\mathrm{N}} \overline{\mathrm{x}}_{\mathrm{N}}\right)+\left(\mathrm{n}_{\mathrm{C}} \overline{\mathrm{x}}_{\mathrm{C}}\right)}{\left(\mathrm{n}_{\mathrm{N}}+\mathrm{n}_{\mathrm{C}}\right)}=96.67$

Normals and carriers are affected to one of the four squares according to the results of both factor VIII activity (y) and Willebrand antigen (x)
A $8 \mathrm{~N}=$ cases $22-25,26,29$, and 30
$3 \mathrm{C}=$ cases 28,33 , and 46
B $\quad 17 \mathrm{~N}=$ cases $1,3,4,7,8,10,11,12,14-20,28$, and 31
$10 \mathrm{C}=$ cases $5-7,12,13,19,24,38,43$, and 49
C $66 \mathrm{~N}=$ cases $2-5,6,9,13$, and 21
$25 \mathrm{C}=$ cases $2-4,9-11,16-18,20-22,25,26,29,30,32$, 34-36, 40-42, 44, and 45
D $11 \mathrm{C}=$ cases $1,8,14,15,23,27,31,37,39,47$, and 48

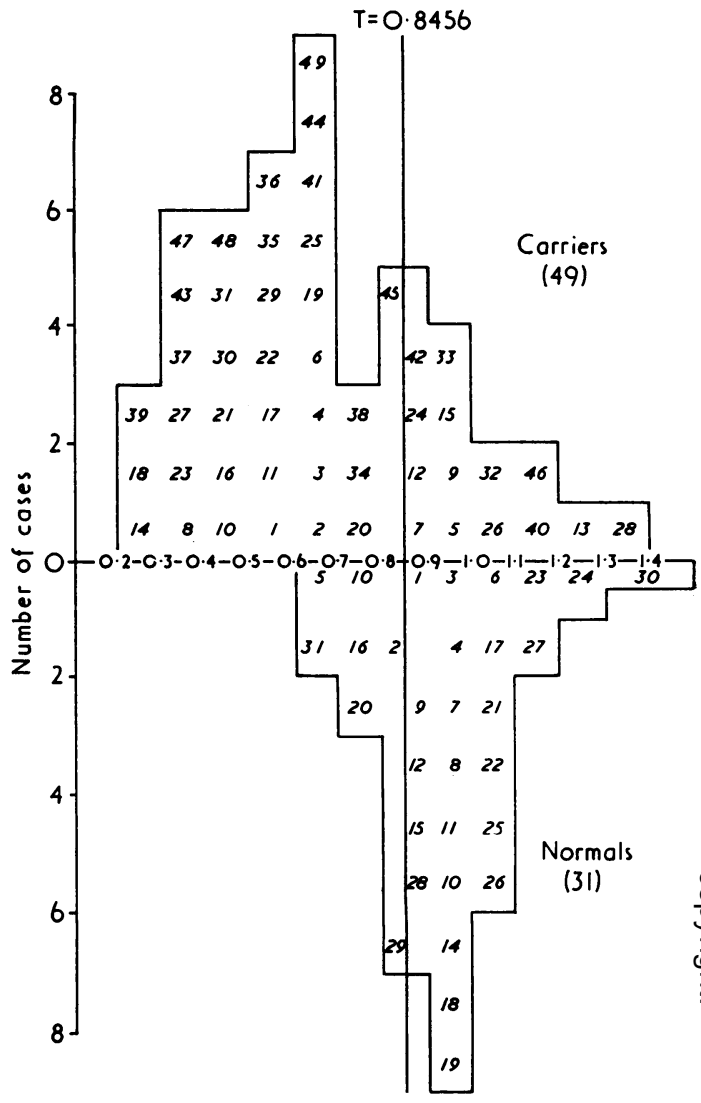

Fig 1 Distribution of the ratio of factor VIII activity to Willebrand antigen in normals (31) and carriers (49): $T=$ discriminant optimized limit to the decision rule of Bayes

$T=h_{N} \frac{R_{N}+h c}{h_{N}+h c} R c=0.8456$

$h$ weighted coefficient $=\frac{1}{\sqrt{2 s^{2}}}$

$s^{2}=$ estimated variance

$N=$ normals

$C=$ carriers

$\bar{R}=$ mean ratio of factor VIII activity to Willebrand antigen.

The small numbers represent the carriers and normals: Misclassified normals: 2, 5, 10, 16, 20, 29, 31 " carriers: $5,7,9,12,13,15,24,26,28$,

$$
32,33,40,42,46
$$

Bayes (T); $22.5 \%$ of the normals ( 7 out of 31 ) and $28.5 \%$ of the carriers (14 out of 49 ) are misclassified.

3. Distribution of the Weighted Mean of Difference between Willebrand Antigen and Factor VIII Activity

The same mode of representation was used, except 


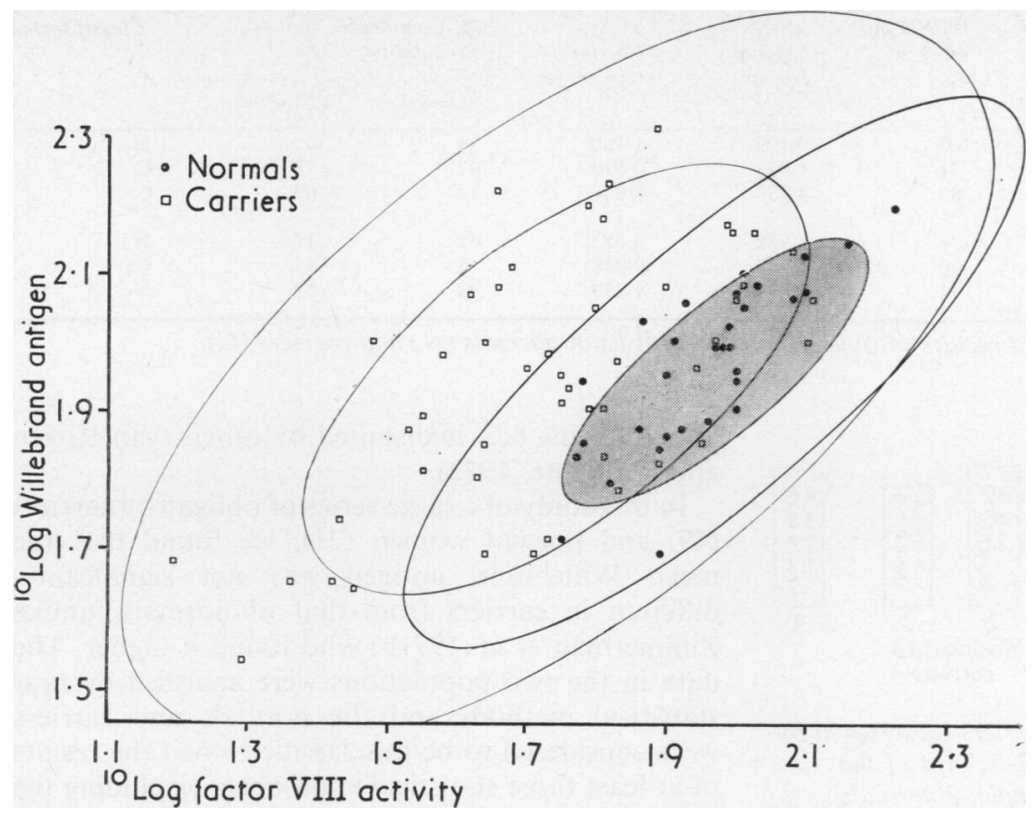

Fig 2 Dispersion diagram of Willebrand antigen and factor VIII activity in normals and carriers, with $50 \%$ (inner) and $95 \%$ tolerance ellipses.

$\lambda^{2}=\frac{1}{1-\rho^{2}}\left[\left(\frac{x-\bar{x}}{s x}\right)^{2}-2 \rho\left(\frac{(x-\bar{x})(y-\bar{y})}{s x s y}\right)+\left(\frac{(y-\bar{y})}{s y}\right)^{2}\right]$

$\lambda^{2}=$ statistical distance (see Methods)

$\rho=$ correlation coefficient

$\boldsymbol{x}=$ factor VIII activity

$y=$ Willebrand antigen

$s=$ standard deviation

The equation shows that each value of $\lambda^{2}$ corresponds to an ellipse. For increasing values of $\lambda^{2}$, these ellipses contain an increasing percentage of the samples studied.

that for this analysis all the results of both assays for the two groups were taken into account, and not only their mean as previously; $29 \%$ of normals and $22.4 \%$ of carriers are misclassified.

\section{Discriminant Analysis}

Figure 2 shows the results of factor VIII activity and Willebrand antigen, transformed in $\log$ values, together with the $50 \%$ and $95 \%$ tolerance ellipses for both groups. These ellipses are different since the correlation coefficient $(\rho)$ is distinct in the two groups. The long axis of the ellipses corresponds to the variability of Willebrand antigen and is similar in both groups; the other axis is quite different since the variability of factor VIII activity is small for the control group and large for the carrier group. The distinction between the two groups studied is not clear since the distance between the centrum of the two ellipses is small.
A discriminant analysis using a computer was then applied to the results. The distance $\left(\lambda^{2}\right)$ of each individual point was calculated to the centrum of both ellipses, and examples of results are given in table III. For case 1 among the normals, the distance towards the centrum of the normal ellipse $(0 \cdot 129)$ was smaller than that towards the centrum of the carrier ellipse (1.760). She had a $94 \%$ confidence probability of belonging to the normal group and $42 \%$ of belonging to the carrier group. Therefore she was classified as normal. For case 33 among the carriers, the distance was smaller towards the centrum of the normal ellipse. She was classified as a normal, with $97 \%$ confidence probability. According to this analysis, 6 out of 31 normals $(19 \cdot 3 \%=$ cases $2,5,9,16,20$, and 31 ) and 9 out of 49 carriers $(18 \cdot 3 \%=$ cases, $5,7,12,13,15,24,28,33$, and 46$)$ are misclassified.

The misclassified normals and carriers according 


\begin{tabular}{|c|c|c|c|c|c|c|c|c|}
\hline & & \multirow{2}{*}{$\begin{array}{l}\text { Factor VIII } \\
\text { Activity } \\
\%\end{array}$} & \multirow{2}{*}{$\begin{array}{l}\text { Willebrand } \\
\text { Antigen } \\
\%\end{array}$} & \multirow{2}{*}{$\begin{array}{l}\lambda^{2} \\
\text { Normal } \\
\text { Group }\end{array}$} & \multirow{2}{*}{$\begin{array}{l}\lambda^{2} \\
\text { Carrier } \\
\text { Group }\end{array}$} & \multicolumn{2}{|c|}{$\begin{array}{l}\% \text { Confidence } \\
\text { Probability }\end{array}$} & \multirow[t]{2}{*}{ Classification } \\
\hline & & & & & & Normal & Carrier & \\
\hline Normals & $\begin{array}{l}1 \\
2 \\
5\end{array}$ & $\begin{array}{l}97 \\
60 \\
60\end{array}$ & $\begin{array}{r}105 \\
71 \\
88\end{array}$ & $\begin{array}{l}0 \cdot 129 \\
1 \cdot 873 \\
4 \cdot 258\end{array}$ & $\begin{array}{l}1 \cdot 760 \\
0.510 \\
0.046\end{array}$ & $\begin{array}{l}94 \\
47 \\
12\end{array}$ & $\begin{array}{l}42 \\
78 \\
97\end{array}$ & $\begin{array}{l}\mathbf{N} \\
\mathbf{C} \\
\mathbf{C}\end{array}$ \\
\hline Carriers & $\begin{array}{r}7 \\
25 \\
33\end{array}$ & $\begin{array}{r}121 \cdot 5 \\
56 \cdot 5 \\
86.5\end{array}$ & $\begin{array}{r}136 \\
90 \\
91\end{array}$ & $\begin{array}{l}1.982 \\
5.965 \\
0.079\end{array}$ & $\begin{array}{l}4 \cdot 383 \\
0 \cdot 038 \\
1 \cdot 213\end{array}$ & $\begin{array}{r}42 \\
6 \\
97\end{array}$ & $\begin{array}{l}12 \\
97 \\
55\end{array}$ & $\begin{array}{l}\mathbf{N} \\
\mathbf{C} \\
\mathbf{N}\end{array}$ \\
\hline
\end{tabular}

Table III Examples of computerized results of a discriminant analysis in normals $(N)$ and carriers $(C)$

${ }^{1}$ See fig 2

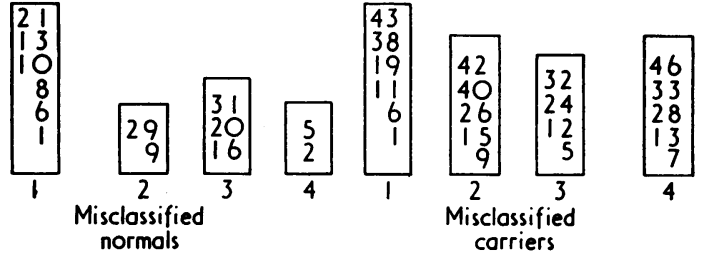

Fig 3 Misclassified normals and carriers (designated by their order number) according to 1, 2, 3, or 4 of the statistical approaches used. For example, 2 normals (cases 2 and 5) and 5 carriers (cases 7, 13, 28, 33 and 46) are misclassified by all (4) statistical approaches.

to the four statistical approaches are listed in fig 3 ; $16 \%$ of normals and $18 \%$ of carriers are misclassified by at least three statistical methods.

\section{Discussion}

The measurement of factor VIII activity alone is a poor way of identifying carriers of haemophilia, except in $30-40 \%$ of them with factor VIII below $50 \%$ on three different occasions (Soulier and Josso, 1966). No judgment can be made concerning the carrier state in a woman whose level of factor VIII is above $50 \%$. It has been stated that estimation of the ratio of factor VIII activity to Willebrand (or factor VIII-related) antigen is of valuable help in genetic counselling for haemophilia A (Zimmerman et al, 1971b; Bennett and Ratnoff, 1973). This specific ratio has been found to increase the score of carrier detection to $92-95 \%$, both studies using the same source of antiserum, and the determination of factor VIII-related antigen being done first on cryoprecipitate (Zimmerman et al, 1971b), then on plasma (Bennett and Ratnoff, 1973). Similar data, but based on the study of only a small number of carriers, were reported by Bennett and Huehns (1970) using an inhibition neutralization technique. According to Bennett and Ratnoff (1973), 50\% of daughters of known heterozygotes (with an even chance of being normal) were tested as carriers, and this detection was also possible in pregnant women, although this fact is disputed by others (van Royen and Ten Cate, 1973).

In this study of a large series of obligatory carriers (49) and normal women (31), we found that the mean Willebrand antigen was not significantly different in carriers from that of normals, unlike Zimmerman et al (1971b) who found it higher. The data in the two populations were analysed by four statistical methods and the normals and carriers were considered to be misclassified when the results of at least three statistical approaches (including the discriminant analysis using a computer) were in agreement. Using such criteria, $16 \%$ of normals and $18 \%$ of carriers were found to overlap with the othe group.

Although the percentage of carriers detected higher when taking into account the results of bot? biological and immunological factor VIII, it is low when compared to the others previously reported (Zimmerman et al, 1971b; Bennett and Ratnoff, 1973). These discrepancies could theoretically be related to technical differences in the assay of both factor VIII activity and Willebrand antigen or to the use of antisera with slightly different specificity. Furthermore, our results were analysed by a different approach from that previously used since both parameters studied (factor VIII activity and Willebrand antigen) are variable. However, our present data are in agreement with those of Bouma et al (1975), Prentice and Forbes (1974), and Zimmerman (1974) who tested another and larger series of carriers. According to these authors, $20-30 \%$ of 'hidden' known carriers are not detected by the methods presently used.

The observation that the plasma of female carriers contains functionally active and antigenically detectable, but inactive, material was reported to be consistent with the Lyon (1961) and Russell (1964) hypothesis of random inactivation of a portion of both normal and mutant $\mathrm{X}$ chromosome. According to this hypothesis, the average concentration of factor VIII activity in carriers should be $50 \%$. Results in individual carriers vary widely; in the extreme case, a carrier might synthesize little or no 
functional factor VIII and because of this be symptomatic. Since it is $\mathrm{X}$ chromosome dependent, the Lyon hypothesis may explain results of factor VIII activity in carriers. However, factor VIII related (or Willebrand) antigen is autosomal dependent and thus the Lyon hypothesis should not be applied to it. It remains to be established whether further progress for the detection of the carrier state will be achieved by refinement of the determination of both factor VIII activity and Willebrand antigen, or whether in a proportion of carriers there may be inactivation of all the $\mathrm{X}$ chromosomes from the abnormal parent, resulting in such a carrier in normal amounts of factor VIII activity. These individuals thus would not be identified by the present methods.

It is not yet known what autosomal dependent entity(ies) is (are) measured with the heterologous antisera employed and what is the relationship between factor VIII activity (X chromosome dependent) and Willebrand antigen (autosomal dependent). Both entities vary in a parallel manner in a number of physiological or non-physiological conditions (Bennett and Ratnoff, 1972; Prentice et al, 1972). However, they may be separated in a number of situations: transfusion in von Willebrand's disease (Bennett et al, 1972), immunoadsorption (Zimmerman and Edgington, 1973) or dissociation with either sodium chloride $1 \mathrm{M}$ (Weiss et al, 1972; Meyer et al, 1974) or calcium chloride $0.25 \mathrm{M}$ (Owen and Wagner, 1972). Thus factor VIII activity and Willebrand antigen seem to be two biologically linked but distinct molecules. If this is so, more data concerning the synthesis and the metabolism of these entities are needed before elucidating with certainty the problem of the detection of carriers.

This work was supported by a grant from INSERM. The technical help of B. Obert is gratefully acknowledged.

\section{References}

Bennett, B. and Ratnoff, O. D. (1972). Changes in antihemophilic factor (AHF, factor VIII) prozoagulant activity and AHF-like antigen in normal pregnancy, and following exercise and pneumoencephalography. J. Lab. clin. Med., 80, 256-263.

Bennett, B. and Ratnoff, O. D. (1973). Detection of the carrier state for classic hemophilia. New Engl. J. Med., 288, 342-345.

Bennett, B., Ratnoff, O. D., and Levin, J. (1972). Immunologic studies in von Willebrand's disease: evidence that the antihemophilic factor (AHF) produced after transfusions lacks an antigen associated with normal AHF and the inactive material produced by patients with classic hemophilia. J. clin. Invest., 51, 2597-2601.

Bennett, E., and Huehns, E. R. (1970). Immunological differentiation of three types of haemophilia and identification of some female carriers. Lancet, 2, 956-958.

Bouma, B. N., van der Kaauw, M. M., Veltkamp, J. J., Starkenburg, A., van Tilburg, N. H., and Hermans, J. M.
H. (1975). Evaluation of the detection rate of hemophilia carriers. Thromb. Res. in press.

Cramer, H. (1967). Equivalence of two methods of computing discriminant function coefficients. Biometrics, 23, 153.

Fisher, R. A. (1936). The use of multiple measurements in taxonomic problems. Ann. Eugen. 7, 179-188.

Hoyer, L. W. (1972). Immunologic studies of antihemophilic factor (AHF, factor VIII). IV. Radioimmunoassay of AHF antigen. J. Lab. clin. Med., 80, 822-833.

Ingram, G. I. C. (1965). Blood coagulation factor VIII. 3. Physiological control. Advanc. clin. Chem., 8, 207-222.

Laurell, C. B. (1966). Quantitative estimation of proteins by electrophoresis in agarose gel containing antibodies. Analyt. Biochem., 15, 45-52.

Lyon, M. F. (1961). Gene action in the X-chromosome of the mouse (Mus musculus L.). Nature (Lond.), 190, 372-373.

Meyer, D., Jenkins, C. S. P., Dreyfus, M. D., Fressinaud, E., and Larrieu, M. J. (1974). Willebrand factor and ristocetin. II. Relationship between Willebrand factor, Willebrand antigen and factor VIII activity. Brit. $J$. Haemat., 28, 579-599.

Meyer, D., Lavergne, J. M., Larrieu, M. J., and Josso, F. (1972). Cross-reacting material in congenital factor VIII deficiencies (haemophilia $\mathbf{A}$ and von Willebrand's disease). Thromb. Res., 1, 183-196.

Owen, W. G. and Wagner, R. H. (1972). Antihemophilic factor: separation of an active fragment following dissociation by salts or detergents. Thrombos. Diathes. haemorrh. (Stuttg.), 27, 502-515.

Peterson, D. W. (1965). Discriminant functions: Properties, classes and computational techniques. Stanf. Electrun. lab. Technol., p. 6761.

Prentice, C. R. M., and Forbes, C. D. (1974). Haemophilia carriers. (Letter) Lancet, 2, 403.

Prentice, C. R. M. Forbes, C. D., and Smith, S. M. (1972). Rise of factor VIII after exercise and adrenaline infusion, measured by immunological and biological techniques. Thromb. Res., 1, 493-506.

Russell, L. B. (1964). Another look at the single-active-X hypothesis. Trans. N. Y. Acad. Sci., 26, 726-736.

Seal, H. L. (1968). Multivariate Statistical Analysis for Biologists. Methuen, London.

Snedecor, G. W. and Cochran, W. G. (1967). Statistical Methods, 6th edition. Iowa State University Press, Ames, Iowa.

Soulier, J. P. and Josso, F. (1966). Current studies in hemophilia. Bibl. haemat. (Basel), 26, 1.

Stites, D. P., Hershgold, E. J., Perlman, J. D., and Fudenberg, H. H. (1971). Factor VIII detection by hemagglutination inhibition: hemophilia A and von Willebrand's disease. Science, 171, 196-197.

van Royen, E. A. and ten Cate, J. W. (1973). Antigen biological activity ratio for factor VIII in late pregnancy. Lancet (Letter) 2, 449-450.

Weiss, H. J., Phillips, L. L., and Rosner, W. (1972). Separation of sub-units of antihemophilic factor (AHF) by agarose gel chromatography. Thrombos. Diathes. haemorrh. (Stuttg.), 27, 212-219.

Zimmerman, T. S. (1974). Personal communication.

Zimmerman, T. S., and Edgington, T. S. (1973). Factor VIII coagulant activity and factor VIII-like antigen : independent molecular entities. J. exp. Med., 138, 1015-1020.

Zimmerman, T. S. Ratnoff, O. D., and Littell, A. S. (1971b). Detection of carriers of classichemophilia using an immunologic assay for antihemophilic factor (factor VIII). J. clin. Invest., 50, 255-258.

Zimmerman, T. S., Ratnoff, O. D., and Powell, A. E. (1971a). Immunologic differentiation of classic hemophilia (factor VIII deficiency) and von Willebrand's disease. $J$. clin. Invest., 50, 244-255. 